\title{
Effects on steroid hormones secretion resulting from the acute stimulation of sectioning the superior ovarian nerve to pre-pubertal rats
}

\author{
Leticia Morales-Ledesma ${ }^{*}$, Elizabeth Vieyra', Deyra A Ramírez ${ }^{1}$, Angélica Trujillo3 ${ }^{3}$ Roberto Chavira², \\ Mario Cárdenas ${ }^{2}$ and Roberto Domínguez ${ }^{1}$
}

\begin{abstract}
In the adult rat, neural signals arriving to the ovary via the superior ovarian nerve (SON) modulate progesterone $\left(\mathrm{P}_{4}\right)$, testosterone $(T)$ and estradiol $\left(E_{2}\right)$ secretion. The aims of the present study were to analyze if the SON in the pre-pubertal rat also modulates ovarian hormone secretion and the release of follicle stimulating hormone (FSH) and luteinizing (LH) hormone. $\mathrm{P}_{4}, \mathrm{~T}, \mathrm{E}_{2}, \mathrm{FSH}$ and $\mathrm{LH}$ serum levels were measured 30 or 60 minutes after sectioning the $\mathrm{SON}$ of pre-pubertal female rats. Our results indicate that the effects on hormone levels resulting from unilaterally or bilaterally sectioning the SON depends on the analyzed hormone, and the time lapse between surgery and autopsy, and that the treatment yielded asymmetric results. The results also suggest that in the pre-pubertal rat the neural signals arriving to the ovaries via the SON regulate the enzymes participating in $P_{4}, T$ and $E_{2}$ synthesis in a non-parallel way, indicating that the mechanisms regulating the synthesis of each hormone are not regulated by the same signals. Also, that the changes in the steroids hormones are not explained exclusively by the modifications in gonadotropins secretion. The observed differences in hormone levels between rats sacrificed 30 and 60 min after surgery reflect the onset of the compensatory systems regulating hormones secretion.
\end{abstract}

Keywords: Superior ovarian nerve, Steroid hormones, Gonadotropins, Pre-pubertal rat

\section{Background}

In the rat, the ovary receives sympathetic innervation via two neural pathways: the ovarian plexus nerve (OPN), which accompanies the ovarian artery, and the superior ovarian nerve (SON), which travels along the suspensory ligament $[1,2]$. The $\mathrm{SON}$ is one of the neural pathways involved in the control of ovarian functions, including puberty onset [3], ovulation [4-6] steroidogenesis, and compensatory ovarian hypertrophy $[7,8]$.

The SON originates at the celiac ganglion, penetrates into the ovary through the hilium, and innervates the ovarian stroma, particularly the theca and secondary interstitial cells. Both of these cells are responsible for androgen synthesis $[1,9,10]$. The sympathetic innervations

\footnotetext{
* Correspondence: moralesledesma@yahoo.com.mx

'Biology of Reproduction Research Unit. Physiology of Reproduction Laboratory, Facultad de Estudios Superiores Zaragoza, UNAM. AP 9-020, CP15000, México, D.F, Mexico

Full list of author information is available at the end of the article
}

reaching the rat's ovary are formed of fibers containing catecholamines, neuropeptide Y (NPY), and vasoactive intestinal peptide (VIP). The fibers that transport catecholamines and VIP are associated with steroidogenic tissue; while the fibers that transport NPY are associated with blood vessels and ovarian interstitial tissue [11-14].

Studies revealed that sectioning or electrically stimulating the SON modifies the secretion rate of ovarian steroids, and that these modifications vary according to the rat's reproductive life stage [15-17]. Weiss et. al. [18] reported that in adult rats, the electrical stimulation of the $\mathrm{SON}$ on diestrus day results in ovarian progesterone $\left(\mathrm{P}_{4}\right)$ secretion increase. Bilaterally sectioning the SON on the morning of proestrus day resulted in an immediate decrease of estradiol $\left(\mathrm{E}_{2}\right)$ and $\mathrm{P}_{4}$ concentrations in plasma, with normal values thereafter [19].

In 4-day old rats, the bilateral section of the SON delays the age of vaginal opening. Animals with the same treatment sacrificed during the pre-pubertal phase,

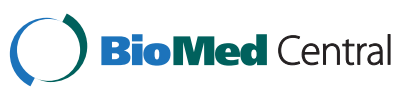


puberty or adulthood showed significant increases in follicle stimulating hormone (FSH) concentrations, with no apparent changes in luteinizing hormone (LH) levels. Based on these results the authors suggested that during the neonatal period the neural information arriving to the ovaries via the $\mathrm{SON}$ is essential for regulating prepubertal development and the cyclic activity of the ovary in the adult animal [3].

The unilateral and bilateral denervation of the ovary resulting from sectioning the SON has different effects on ovulation $[4,6]$. In both, pre-pubertal and adult rats, the bilateral sectioning of the SON did not modify ovulation rates (number of ovulating animals) nor the number of ova shed $[4,6,20]$. Unilateral sectioning the SON resulted in lower ovulation rates and number of ova shed by the denervated ovary [6]. The subsequent injection of gonadotropins did not restore ovulation by the denervated ovary. These results suggest that the neural information carried to the ovaries via the SON innervation modulates the responsiveness of the ovarian compartments to gonadotropins; and that such response is stimulatory and asymmetrical [21].

The bilateral section of the SON of 2-day old rats resulted in lower number and smaller sized ovarian follicles, a reduced sensitivity to gonadotropins, enhanced follicular atresia, and higher $E_{2}$ serum levels when the animals reached the age of 30 or 90-days. Based on these results the authors suggested that the information supplied to the ovaries via the sympathetic nerve plays an important role in regulating follicle development and ovarian function [17].

To our knowledge, the acute effects on steroidogenesis and gonadotropin secretion resulting from the unilaterally or bilaterally sectioning the SON of pre-pubertal rats is unknown. The aim of this study was to analyze the acute stimulatory/inhibitory effects on $\mathrm{P}_{4}$, testosterone $(\mathrm{T}), \mathrm{E}_{2}, \mathrm{FSH}$ and $\mathrm{LH}$ serum levels resulting from the unilateral or bilateral sectioning of the SON.

\section{Methods}

All experiments were carried out in strict accordance with the Mexican Law of Animal Treatment and Protection Guidelines. The Committee of the Facultad de Estudios Superiores Zaragoza approved the experimental protocols.

Female rats of the CII-ZV strain from our own breeding stock were kept with their dams until 21 days old, time when the animals were weaned and placed in acrylic cages in groups of five females and one male per cage. The animals were maintained under controlled conditions of light (lights on from 05:00am to 19:00pm) and temperature $\left(22 \pm 2^{\circ} \mathrm{C}\right)$, with free access to rat food (Purina S.A., Mexico) and water.

Groups of rats were randomly allotted to one of the following treatments:

\section{Untouched - control animals}

A group of ten 32-days old untouched animals was sacrificed for control purposes.

\section{Laparotomy (sham surgery)}

Laparotomy (LAP) was considered the sham-surgery treatment, and its procedures were performed following methodologies previously described [22]. In brief, the animals were anesthetized and an incision affecting skin, muscle, and peritoneum was performed $2 \mathrm{~cm}$ below the last rib. No organs were manipulated. The wound was subsequently sealed.

A group of ten rats was treated with a unilateral dorso-lateral incision on the left side (L-LAP) and a group of ten rats on the right side (R-LAP). A group of nine rats was treated with bilateral dorso-lateral incisions (B-LAP).

\section{Unilateral or bilateral sectioning the SON}

Groups of 10 rats each with unilateral section of the left (L-SON), right (R-SON), or bilateral section of the SON (B-SON), were included. SON sectioning procedures were performed following methodologies previously described [6]. In brief, the animals were anesthetized with ether, laparotomized and a lateral incision was performed as described above. Then, one or both ovaries were exposed and with the aid of fine forceps the ovarian ligament was sectioned approximately $1 \mathrm{~cm}$ from the ovary. The wound was subsequently sealed. Surgical procedures were performed between 09:00 AM and 11:00 AM.

\section{Autopsy procedures}

Animals in each treatment group were sacrificed by decapitation 30 or 60 minutes after treatment. The blood of the trunk was collected, allowed to clot at room temperature for 30 minutes and centrifuged at 3,000 RPM for 15 minutes. Serum was stored at $-20^{\circ} \mathrm{C}$, until $\mathrm{P}_{4}, \mathrm{~T}, \mathrm{E}_{2}, \mathrm{FSH}$ and $\mathrm{LH}$ concentrations were measured. Ovaries were removed, dissected and weighed on a precision balance. To confirm the SON had been properly sectioned, during autopsy it was verified that the ovary was free in the abdominal cavity.

\section{Hormone measurement}

Serum concentrations of $\mathrm{P}_{4}(\mathrm{ng} / \mathrm{ml}), \mathrm{T}$, and $\mathrm{E}_{2}(\mathrm{pg} / \mathrm{ml})$ were measured using radioimmunoassay (RIA) techniques, with kits purchased from Diagnostic Products (Los Angeles, CA, USA). The intra- and inter-assay coefficients of variation for $\mathrm{P}_{4}$ were $8.35 \%$ and $9.45 \%$, for $E_{2} 8.12 \%$ and $9.28 \%$, and for $T 9.65 \%$ and $10.2 \%$, respectively.

$\mathrm{LH}$ and FSH levels in serum $(\mathrm{ng} / \mathrm{ml})$ were measured using the double antibody RIA technique, using reagents 
and protocols kindly supplied by the NIADDK National Pituitary Program (Bethesda, MD, USA). Intra- and inter-assay variations for $\mathrm{LH}$ were in the order of $5.1 \%$ and $6.5 \%$, and $4 \%$ and $7.9 \%$ for FSH. The results are expressed in terms of NIADDK standards RP-2 FSH and $\mathrm{LH}$.

\section{Statistical analyses}

Data on $\mathrm{P}_{4}, \mathrm{~T}, \mathrm{E}_{2}, \mathrm{FSH}$ and $\mathrm{LH}$ concentrations in serum were analyzed using multivariate analysis of variance (MANOVA), followed by Tukey's test. Differences in the concentration of hormones in serum between two groups were analyzed with Student's t-test. A $p$ value of less than 0.05 was considered significant.

\section{Results}

\section{LAP effects on $P_{4}, T$ and $E_{2}$ serum levels}

Compared to the control group, animals with unilateral or bilateral LAP treatment sacrificed 30 minutes after treatment, and bilaterally LAP treated animals sacrificed 60 minutes after treatment showed higher $\mathrm{P}_{4}$ serum levels (Figure 1).

$T$ levels were higher in L-LAP rats sacrificed 30 minutes after surgery and in R-LAP and B-LAP rats sacrificed 60 minutes after surgery (Figure 2).

$\mathrm{E}_{2}$ levels were lower in animals with unilateral or BLAP treatment sacrificed 30 minutes after treatment, and higher in L-LAP and R-LAP animals sacrificed 60 minutes after surgery (Figure 3). B-LAP had no apparent effects on $E_{2}$ levels in animals sacrificed 60 minutes after surgery.

\section{Effects of sectioning the SON on $\mathrm{P}_{4}, \mathrm{~T}, \mathrm{E}_{2}, \mathrm{FSH}$ and $\mathrm{LH}$ serum levels}

Compared to their respective sham-surgery group, $\mathrm{P}_{4}$ concentrations were lower in L-SON and B-SON treated animals sacrificed 30 minutes after surgery and higher in animals with L-SON sacrificed 60 minutes after surgery (Figure 1).

Compared to their respective sham-surgery group, $\mathrm{T}$ concentrations were lower in L-SON treated animals sacrificed 30 minutes after surgery. $\mathrm{T}$ concentrations were higher in L-SON and B-SON treated animals sacrificed 60 minutes after surgery (Figure 2).

Compared to their respective sham-surgery group, $E_{2}$ levels were higher in R-SON treated rats sacrificed 30 minutes after surgery, and lower in L-SON treated animals sacrificed 60 minutes after surgery (Figure 3).

Compared to their respective sham-surgery group, FSH levels were higher in B-SON treated rats sacrificed 30 minutes after surgery, and lower in R-SON animals sacrificed 60 minutes after surgery. Sectioning the LSON or R-SON resulted in lower LH levels than in the L-LAP or R-LAP treatment groups (Table 1).

\section{Discussion}

As previously proposed for adult animals [19,23], the results obtained in the present study suggest that the SON innervation arriving to the ovaries of pre-pubertal rats plays a role regulating $\mathrm{P}_{4}, \mathrm{~T}$, and $\mathrm{E}_{2}$ secretion. However, there is a difference between pre-pubertal and adult animals in their hormone secretion ability, suggesting that in the pre-pubertal stage of the animal the neural, and even perhaps the hormone regulation system, is not mature. Another possibility that may explain such difference is the time of the day when the animals were treated (9:00-11:00 in pre-pubertal animals and 13:00 $\mathrm{h}$ in adult) [23]

The juvenile period extends from day 22 to days 30-32, when the pulsatile release of $\mathrm{LH}$ begins. The peri-puberal period extends to the observation of first ovulation, approximately on day 38 of age [24]. This ovarian

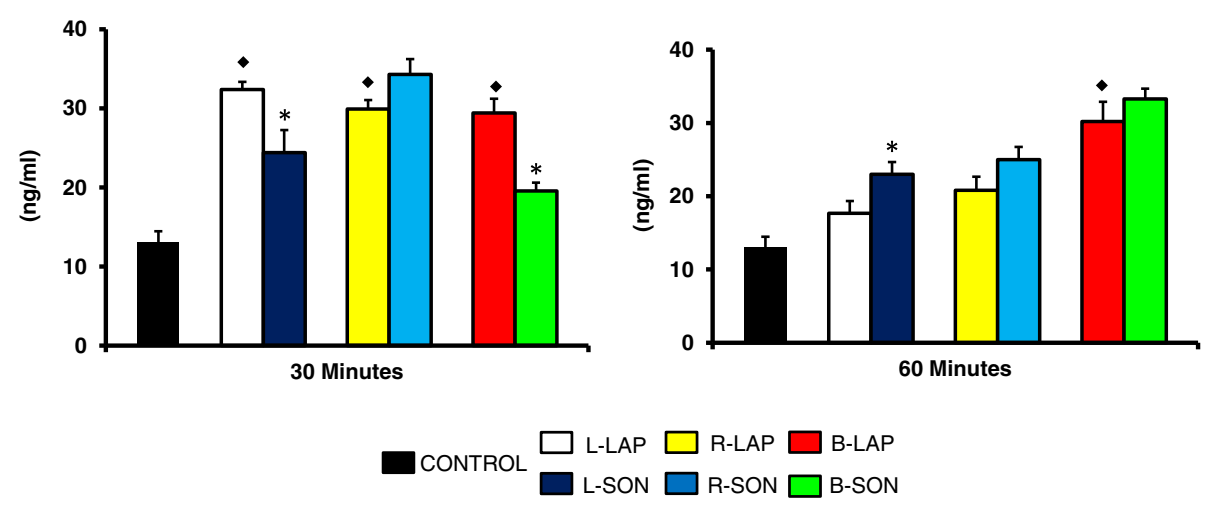

Figure 1 Progesterone $\left(\mathrm{P}_{4}\right)$ serum levels in rats with unilateral or bilateral sectioning of the superior ovarian nerve (SON). Mean \pm S.E.M. of $\mathrm{P}_{4}$ levels in serum. Left (L-LAP), right (R-LAP), bilateral (B-LAP) laparotomy, with sectioning of the left superior ovarian nerve (L-SON), right (RSON) or bilateral (B-SON) performed to 32 days of age. Animals were sacrificed 30 or 60 minutes after surgery. $p<0.05$ vs. control (MANOVA followed by a Tukey/s test).* $<0.05$ vs. its respective LAP group (Student/s t-test). $\bullet$ indicating vs. control group. 


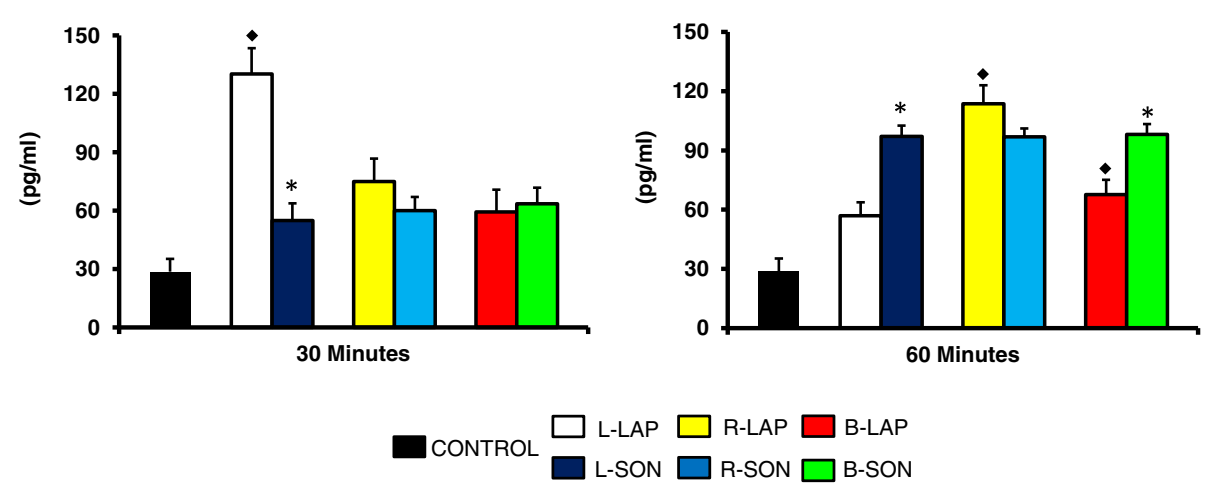

Figure 2 Testosterone (T) serum levels in rats with unilateral or bilateral sectioning of the superior ovarian nerve (SON). Mean \pm S.E.M. of T levels in serum. Left (L-LAP), right (R-LAP), bilateral (B-LAP) laparotomy, with sectioning of the left superior ovarian nerve (L-SON), right (R-SON) or bilateral (B-SON) performed on 32 days of age. Animals were sacrificed 30 or 60 minutes after surgery. $p<0.05$ vs. control (MANOVA followed by a Tukey/s test).* ${ }^{*}<0.05$ vs. its respective LAP group (Student/s t-test). indicating vs. control group.

development stage is regulated by a complex neuroendocrine mechanism, including neural signals that originate in the ovary, since the beginning of the primordial follicles development is stimulated by the sympathetic innervation $[25,26]$.

Present results don't show parallelism between the effects of sham surgery and unilateral or bilateral denervation treatment on $\mathrm{P}_{4}, \mathrm{~T}, \mathrm{E}_{2} \mathrm{FSH}$ and $\mathrm{LH}$ concentrations. This suggests that the observed differences in hormone concentrations are the result of the ovarian denervation. Sectioning the SON provokes an acute neural stimulus that travels through the proximal and distal ends of the nerve. Gerendai et al. [27] showed that neural fibers arising from the ovaries carry neural information to the hypothalamus, and that such information participates in regulating gonadotropins secretion [27]. Since the denervated ovary still receives neural information through the OPN and the vagus nerve [28], our results may reflect the imbalance between the neural signals arriving to the ovaries and the circulating gonadotropins.

In the adult rat, the acute effects resulting from unilateral or bilateral laparotomy on $\mathrm{P}_{4}, \mathrm{~T}$, and $\mathrm{E}_{2}$ serum levels could be partially explained by the activation of a neural pathway that originates in the abdominal wall and/or the peritoneum and arrives to the central nervous system (CNS), ovaries and adrenals. Studies have shown that such neural information varies during the estrous cycle [29-31] and the age of the animal [22]. Uchida et al. [32] showed that mechanically stimulating the abdominal wall or the hind-paw of adult rats modifies ovarian blood flow and the neural activity of the SON. Based on their results, Uchida et al. suggested the existence of spinal reflexes that depend on the laterality (dorsal or ventral) of the stimulus, and supra-spinal reflexes that do not depend on stimulus laterality.

According to Flores et al. [33], the neural information arising from the dorso-lateral abdominal wall plays a
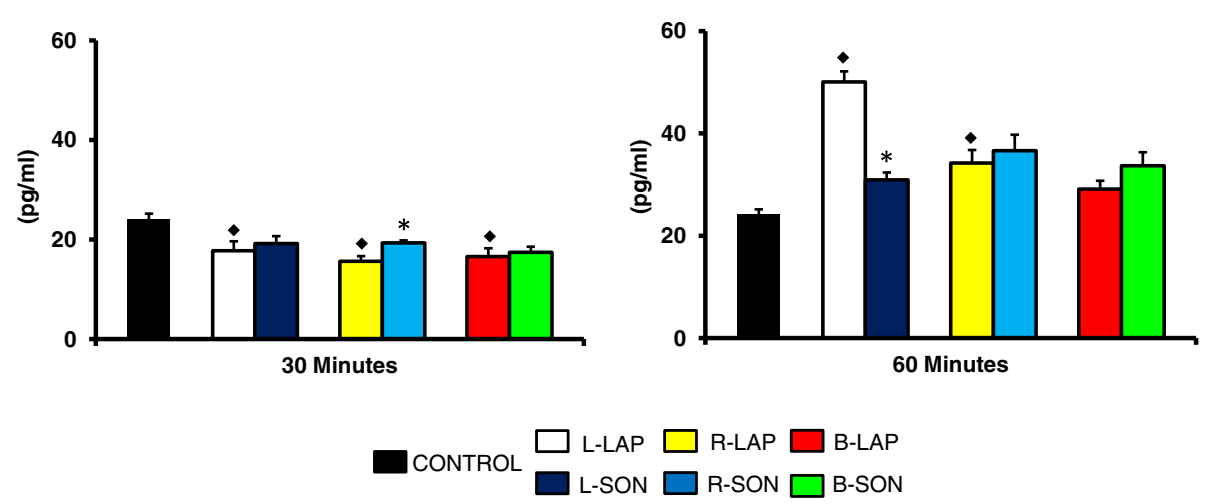

Figure 3 Estradiol $\left(E_{2}\right)$ serum levels in rats with unilateral or bilateral sectioning of the superior ovarian nerve (SON). Mean \pm S.E.M. of $E_{2}$ levels in serum. Left (L-LAP), right (R-LAP), bilateral (B-LAP) laparotomy, with sectioning of the left superior ovarian nerve (L-SON), right (R-SON) or bilateral (B-SON) sectioning performed on 32 days of age. Animals were sacrificed 30 or 60 minutes after surgery. $p<0.05$ vs. Control (MANOVA followed by a Tukey/s test).* ${ }^{*}<0.05$ vs. its respective LAP group (Student/s t-test). • indicating vs. control group. 
Table $1 \mathrm{FSH}$ and $\mathrm{LH}$ serum levels in rats with unilateral or bilateral sectioning of the superior ovarian nerve (SON)

\begin{tabular}{llllll}
\hline & FSH & & & LH \\
\cline { 2 - 3 } \cline { 5 - 6 } Groups & $\mathbf{3 0 ^ { \prime }}$ & $\mathbf{6 0}^{\prime}$ & & $\mathbf{3 0 ^ { \prime }}$ & $\mathbf{6 0}^{\prime}$ \\
\hline Control & $1.0 \pm 0.2$ & $1.0 \pm 0.3$ & & $0.4 \pm 0.05$ & $0.4 \pm 0.05$ \\
L-LAP & $0.8 \pm 0.2$ & $0.7 \pm 0.09$ & & $0.7 \pm 0.03$ & $0.6 \pm 0.08$ \\
L-SON & $0.5 \pm 0.08$ & $0.6 \pm 0.09$ & & $0.5 \pm 0.04^{*}$ & $0.4 \pm 0.07$ \\
R-LAP & $0.7 \pm 0.2$ & $1.1 \pm 0.1$ & & $0.5 \pm 0.04$ & $0.4 \pm 0.09$ \\
R-SON & $0.6 \pm 0.08$ & $0.5 \pm 0.2^{*}$ & & $0.4 \pm 0.05^{*}$ & $0.4 \pm 0.1$ \\
B-LAP & $0.4 \pm 0.06$ & $0.5 \pm 0.03$ & & $0.4 \pm 0.03$ & $0.3 \pm 0.03$ \\
B-SON & $1.3 \pm 0.2^{*}$ & $0.5 \pm 0.09$ & & $0.4 \pm 0.05$ & $0.4 \pm 0.06$ \\
\hline
\end{tabular}

Mean \pm S.E.M. of FSH and LH levels in serum. Left (L-LAP), right (R-LAP), bilateral (B-LAP) laparotomy, with sectioning of the left superior ovarian nerve (L-SON), right (R-SON) or bilateral sectioning (B-SON) performed to 32 days of age. Animals were sacrificed 30 or 60 minutes after surgery. $p<0.05$ vs. control (MANOVA followed by a Tukey/s test). ${ }^{*} p<0.05$ vs. its respective LAP group (Student/s t-test)

$p<0.05$ vs. control (MANOVA followed by a Tukey/s test). ${ }^{*} p<0.05$ vs. its respective LAP group (Student/s t-test).

different role in regulating the secretion of ovarian steroid hormones $\left(\mathrm{P}_{4}, \mathrm{~T}\right.$ and $\left.\mathrm{E}_{2}\right)$ than the information arising from the ventral wall.

In the adult cyclic rat the adrenals are the main source of $\mathrm{P}_{4}$ secretion, while the ovaries are the main source of $\mathrm{T}$ and $\mathrm{E}_{2}$ during the cycle depending the day of the cycle studied [33]. Since the pre-pubertal rat lacks corpora lutea we presume that the increase in $\mathrm{P}_{4}$ secretion observed in rats sacrificed $30 \mathrm{~min}$ after unilateral or bilateral laparotomy was secreted by the adrenals. Such increase could be explained by an increased release of adrenocorticotropic hormone (ACTH) by the pituitary; likely prompted by both, the anesthesia and the perforation of the dorso-lateral abdominal wall. There is evidence that the adrenals and ovaries share neural information through the celiac-superior mesenteric ganglion [34]. Then, the lower levels of $\mathrm{P}_{4}$ observed in LSON and B-SON treated rats would reflect changes in the neural signals arriving to the adrenals. Another, nonexclusive possibility is that the theco-interstitial gland of the ovaries secretes $\mathrm{P}_{4}$ and that the left $\mathrm{SON}$ participates in the regulation of ovarian $\mathrm{P}_{4}$ secretion.

The $\mathrm{P}_{4}$ levels increases in rats with LAP or SON sectioning treatment sacrificed $60 \mathrm{~min}$ after treatment would reflect the start of the system's adaptation to the stimulatory/inhibitory signals arising from the abdominal wall and/ or from the ovaries, and even perhaps from the adrenals.

$\mathrm{P}_{4}$ is a substrate for $\mathrm{T}$ synthesis, which in turn is a substrate for $E_{2}$ synthesis [35]. In the present study, $\mathrm{P}_{4}$ and $\mathrm{T}$ levels increases were parallel, while changes in $\mathrm{T}$ and $E_{2}$ levels were not. These results suggest that the mechanisms regulating the synthesis of each hormone are not regulated by the same signals [36]. Using the ex vivo coeliac ganglion-superior ovarian nerve-ovary (CG-SON-O) model, Delgado et al. [8] described that the expression of 3 beta-hydroxysteroid dehydrogenase (3-HSD) and P450 aromatase are modulated by noradrenergic or cholinergic vias.

Sectioning the OPN [16] or the SON [19] alters $E_{2}$ secretion from the ovary. The lower levels of $\mathrm{E}_{2}$ observed in animals sacrificed $60 \mathrm{~min}$ after SON sectioning suggests that in the pre-pubertal rat the left $\mathrm{SON}$ regulates $\mathrm{E}_{2}$ secretion in a stimulatory way. Kagitani et al., [15] suggested that the $\mathrm{SON}$ inhibits ovarian $\mathrm{E}_{2}$ secretion, while Flores et al. [23] showed that the participation of the $\mathrm{SON}$ on steroid hormone secretion by the ovaries depends on the day of the estrous cycle. Without discarding that the right ovary has a greater capacity to secrete $E_{2}$ [22], these differences could be attributed to the maturity stage of the rat.

VIP is a neurotransmitter present in the SON's neural fibers [37] that stimulates aromatase cytochrome P450c17 activity [38] and the resulting increase of E2 synthesis [39]. Then, it is possible that sectioning the SON of pre-pubertal rats removed VIPergic fibers, resulting in, lower aromatase activity and consequently lower $\mathrm{E}_{2}$ concentrations.

The lack of significant LH level changes, together with the non-parallel changes between FSH concentrations with $T$ and $E_{2}$ levels suggests that the variations in ovarian hormones levels results from altering the ovarian innervation induced by the surgery.

Since sectioning the SON could affect the ovarian artery that is associated with the suspensory ligament and travels parallel to the SON, present results may also be influenced by changes in ovarian blood flow. According to Aguado and Ojeda [19], sectioning the SON affects $\mathrm{P}_{4}$ and $E_{2}$ secretion depending on the day of the cycle, but does not alter ovarian blood flow. Kagitani et al. [15,40] showed that activating the SON may decrease $E_{2}$ synthesis in the ovary, and that the ovarian venous plasma flow rate was equally decreased by stimulating the $\mathrm{SON}$ or the OPN. The authors assume that the reduction rate of $\mathrm{E}_{2}$ secretion by $\mathrm{SON}$ stimulation was due to the direct inhibitory effects of the $\mathrm{SON}$ on $\mathrm{E}_{2}$ synthesis in the ovary rather than to a reduction of ovarian blood flow. The authors conclude that ovarian vascular and $E_{2}$ secretory responses to SON activation are respectively mediated by alpha 1 - and alpha 2-adrenoceptors. The asymmetrical response in steroid ovarian hormones levels to unilateral sectioning of the SON support the idea that neural signals carried by the nerve participate in the regulation of hormone secretion. The results also suggest that the neural participation of enzymes participating in the synthesis of $\mathrm{P}_{4}, \mathrm{~T}$, and $\mathrm{E}_{2}$ is different and asymmetric.

\section{Conclusions}

Present results indicate that, in the pre-pubertal rat the neural signals arriving to the ovaries via the SON 
regulate the enzymes participating in $\mathrm{P}_{4}, \mathrm{~T}$, and $\mathrm{E}_{2}$ synthesis in a non-parallel way. This suggests that the mechanisms regulating the synthesis of each hormone are not regulated by the same signals, and that the changes in the steroids hormone levels are not explained by the modifications in gonadotropin secretion.

\section{Competing interests}

The authors declare that they have no competing interests.

\section{Authors' contributions}

LM and RD planned the experiments. LM, EV, DAR, AT and RD devised the study and participated in the discussion of the results. RC and MC participated in performing the RIA's to measure the different hormones levels. All authors read and approved the final manuscript.

\section{Acknowledgements}

This work was supported by the PAPIIT- DGAPA IN213110. We want to thank M Sc A. Domínguez for the revision of the manuscript in English.

\section{Author details}

'Biology of Reproduction Research Unit. Physiology of Reproduction Laboratory, Facultad de Estudios Superiores Zaragoza, UNAM. AP 9-020, CP15000, México, D.F, Mexico. Instituto Nacional de Ciencias Médicas y Nutrición "Salvador Zubirán", México, D.F, México. ${ }^{3}$ Escuela de Biología, Benemérita Universidad Autónoma de Puebla, Puebla, Mexico.

Received: 18 June 2012 Accepted: 21 October 2012

Published: 30 October 2012

\section{References}

1. Burden HW: The adrenergic innervation of mammalian ovaries. In Serono symposia publications from Raven Press, Volume 18. Edited by Ben-Jonathan N, Bahr JM, Weiner Rl. New York: Catecholamines as hormone regulators Raven Press; 1985:261-278.

2. Lawrence IE, Burden HW: The origin of the extrinsic adrenergic innervation to the rat ovary. The Anatomical Record 1980, 196:51-59.

3. Forneris ML, Aguado LI: Neonatal superior ovarian nerve transection disturbs the cyclic activity of the female rats. Journal of Steroid Biochemistry and Molecular Biology 2002, 82:75-82.

4. Chávez R, Carrizosa L, Domínguez R: Effects of superior ovarian nerve section on spontaneous and induced ovulation in adult rats. Medical Science Research 1991, 19:41-42.

5. Luna F, Cortés M, Flores M, Hernández B, Trujillo A, Domínguez R: The effects of superior ovarian nerve sectioning on ovulation in the guinea pig. Reproductive Biology and Endocrinology 2003, 1(61):1-7.

6. Morales $L$, Chávez R, Domínguez R: Participation of the superior ovarian nerve in the regulation of ovulation in the pre-pubertad rat: differential effects of unilateral and bilateral section of the nerve. Medical Science Research 1993, 21:15-17.

7. Chávez R, Domínguez R: Participation of the superior ovarian nerve in the regulation of compensatory ovarian hypertrophy: the effects of its section performed on each day of the oestrous cycle. J. Endocrinol 1994, 140:197-201.

8. Delgado SM, Escuderoa CG, Casais M, Gordillo M, Ana Cecilia Anzulovich AC, Sosa Z, Rastrilla AM: Ovaric-physiology in the first oestral cycle: Influence of noradrenergic andcholinergic neural stimuli from coeliac ganglion. Steroids 2010, 75:685-694.

9. Dissen AG, Ojeda SR: Innervation in ovarian. In Encyclopedia of Reproduction. Vol 3rd edition. Edited by Ernst K, Jimmy D. Neill. Academic Press; 1999:583-589.

10. Erickson GF, Magofin DA, Dyer CA, Hofeditz C: The ovarian androgenproducing cells: a review of structure/function relationships. Endocrinol 1985, 6:371-399.

11. Dess WL, Ahmed CE, Ojeda SR: Substance P and vasoactive intestina peptide containing fibers reach the ovary by independent routes. Endocrinology 1986, 119:638-641.

12. Ferruz J, Ahmed CE, Ojeda SR, Lara HE: Norepinephrine release in the immature ovary is regulated by autoreceptors and neuropeptide $Y$. Endocrinology 1992, 130:1345-1351.
13. McDonald JK, Dess WL, Ahmed CE: Biochemical and immunocytochemical characterization of neuropeptide $Y$ in the immature rat ovary. Characterization. Endocrinology 1987, 120:1703-1710.

14. Papka RE, Cotton JP, Trauring HH: Comparative distribution of neuropeptide tyrosine, vasoactive intestinal polypeptide, substance $P$ immunoreactive, acetylcholinesterase positive and noradrenergic nerves in the reproductive tract of the female rat. Cell Tissue Res 1985, 242:475-490.

15. Kagitani F, Uchida S, Hotta H: Effects of electrical stimulation of the superior ovarian nerve and the ovarian plexus on the ovarian estradiol secretion rate in rats. The Journal of Physiological Sciences 2008, 58(2):133-138.

16. Kawakami M, Kubo K, Uemura T, Nagase M, Hayashi R: Involvement of ovarian innervation in steroid secretion. Endocrinology 1981, 109:136-145.

17. Zhang $X$, Zhang L, Huo S, Wang J, Cui S: Neonatal superior ovarian nerve transaction inhibits follicle development by enhancing follicular atresia and suppressing granulose cell proliferation in rats. Reproduction, Fertility and Development 2010, 22:1148-1158

18. Weiss GK, Dail WG, Ratner A: Evidence for direct neural control of ovarian steroidogenesis in rats. Journal of Reproduction and Fertility 1982 65:507-511.

19. Aguado L, Ojeda SR: Ovarian adrenergic nerves play a role in maintaining pre-ovulatory steroid secretion. Endocrinology 1984, 114:1944-1946.

20. Selstam G, Norjavaara E, Tegenfelt T, Lundberd S, Sandström C, Persson S: Partial denervation of the ovaries by transaction of the suspensory ligament does not inhibit ovulation in rats treated with pregnant mare serum gonadotropin. The Anatomical Record 1985, 213:392-395.

21. Morales L, Chávez R, Ayala ME, Domínguez R: Effects of unilateral or bilateral superior ovarian nerve section in pre-pubertal rats on the ovulatory response to gonadotrophin administration. Journal of Endocrinology 1998, 158:213-219.

22. Morales L, Ramírez D, Vieyra E, Trujillo A, Chavira R, Cardenas M, Domínguez R: The effects acute unilateral ovariectomy pre-pubertal rat on steroid hormones secretion and compensatory ovarian responses. Biology of Reproduction 2011, 9(41):1-8.

23. Flores A, Velasco J, Gallegos A, Mendoza F, Everardo P, Cruz ME, Domínguez R: Acute effects of unilateral sectioning the superior ovarian nerve of rats with unilateral ovariectomy on ovarian hormones (progesterone, testosterone and estradiol) levels vary during the estrous cycle. Reproductive Biology and Endocrinology 2011, 9(34):1-11.

24. Urbanski HF, Ojeda SR: The juvenile-peripuberal transition period in the female rat: establishment of a diurnal pattern of pulsatile luteinizing hormone secretion. Endocrinology 1985, 117:644-649.

25. Ojeda SR, Costa M, Katz KH, Hersh LB: Evidence for the existence of substance $\mathrm{P}$ in the pre-pubertal rat ovary. I. Biochemical and physiological studies. Biol Reprod 1985, 33:286-295.

26. Casais M, Delgado SM, Sosa Z, Rastrilla AM: Involvement of the coeliac ganglion in theluteotrofic effect of androstenedione in late pregnant rats. Reproduction 2006, 131:361-368.

27. Gerendai I, Tóth IE, Boldogkoi Z, Halász B: Recent findings on the organization of central nervous system structures involved in the innervation of endocrine glands and other organs; observations obtained by the transneuronal viral double-labeling technique. Endocrine 2009, 36(2):179-188.

28. Domínguez R, Cruz-Morales SE: The ovarian innervation participates in the regulation of ovarian functions. Endocrinol Metabol Syndrome 2011, S4:1-10.

29. Barco Al, Flores A, Chavira R, Damián-Matsumura P, Domínguez R, Cruz ME: Asymmetric effects of acute hemiovariectomy on steroid hormone secretion by the in situ ovary. Endocrine 2003, 21:209-215.

30. Flores A, Meléndez G, Palafox MT, Rodríguez OJ, Barco Al, Chavira R, Domínguez R, Cruz ME: The participation of the cholinergic system in regulating progesterone secretion through the ovarian-adrenal crosstalk varies along the estrous cycle. Endocrine 2005, 2:1-7.

31. Cruz ME, Flores A, Palafox MT, Mélendez G, Rodríguez OJ, Chavira R, Domínguez $R$ : The role of the muscarinic system in regulating estradiol secretion varies during the estrous cycle: the hemiovariectomized rat model. Reproductive Biology and Endocrinology 2006, 4(43):1-8.

32. Uchida S, Kagitani F, Hotta H, Hanada T, Aikawa Y: Cutaneous Mechanical Stimulation Regulates Ovarian Blood Flow via Activation of Spinal and 
Supra-spinal Reflex Pathways in Anesthetized Rats. Jpn J Physiol 2005, 55(5):265-277.

33. Flores A, Gallegos A, Velasco J, Mendoza F, Montiel C, Everardo P, Cruz ME, Domínguez R: The acute effects of bilateral ovariectomy on progesterone, testosterone and estradiol serum levels depend on the surgical approach and the day of the estrous cycle when they are performed. Reproductive Biology and Endocrinology 2008, 6(48):1-7.

34. Tóth I, Banczerowski P, Boldogko Z, Tóth J, Szabó A, Halász B, Gerendai I: Cerebral neurons involved in the innervation of both the adrenal gland and the ovary: A double viral tracing study. Brain Research Bulletin 2008, 77:306-311.

35. Strauss JR III, Hsueh AJW: Ovarian hormone synthesis. In Endocrinology Fourth edition, Volume Chap. 148. Vol 3rd edition. Edited by De Groot $\sqcup$, Jameson JL. Philadelphia, Pennsylvania: WB Saunders Co; 2000:2043-2052. ISBN 0-7216-7840-8 (set).

36. Domínguez R, Flores A, Cruz-Morales SE: Hormonal and Neural Mechanisms Regulating Hormone Steroids Secretion. In Steroids Basic Science. Chap. 1st edition. Edited by Hassan A.: Publisher In Tech; 2011:3-32. ISBN 978-953-307-866-3.

37. Klein CM, Burden HW: Substance $P$ and vasoactive intestinal polypeptide (VIP) inmunoreactive nerve fibers in relation to ovarian post-ganglionic perikarya in para and pre-vertebral ganglia: evidence from combined retrograde tracing and immunocytochemistry. Cell Tissue Res 1988, 252:403-410.

38. George FW, Ojeda SR: Vasoactive intestinal peptide induces aromatase activity before development of primary follicles and responsiveness to FSH. Proc Natl Acad Sci USA 1987, 84:5803-5807.

39. Davoren BJ, Hsueh AJW: Vasoactive intestinal peptide: a novel stimulator of steroidogenesis by cultured rat granulosa cells. Biol Reprod 1984, 33:37-52.

40. Kagitani F, Uchida S, Hotta H: The role of alpha adrenoceptors in the vascular and estradiol secretory responses to stimulation of the superior ovarian nerve. J Physiol Sci 2011, 61:247-251.

doi:10.1186/1477-7827-10-88

Cite this article as: Morales-Ledesma et al: Effects on steroid hormones secretion resulting from the acute stimulation of sectioning the superior ovarian nerve to pre-pubertal rats. Reproductive Biology and Endocrinology 2012 10:88

\section{Submit your next manuscript to BioMed Central and take full advantage of:}

- Convenient online submission

- Thorough peer review

- No space constraints or color figure charges

- Immediate publication on acceptance

- Inclusion in PubMed, CAS, Scopus and Google Scholar

- Research which is freely available for redistribution 